\title{
Personage Column: GONG Feili
}

Prof. Gong Feili was born and raised in Shanghai, China. He attended Sun Yat-sen Medical College, Guang zhou during 1962 to 1968 , and received his M.D. degree there in 1968. After graduation, he worked as a physician in the Department of Internal Medicine of the Wugang Hospital, Wuhan, from 1968 to 1980. During that period of time, cases of leukemia drew his attention, and made him interested in immunology. He started his research work in the Department of Pathophysiology, Wuhan Medical College in 1980, focusing on the function of macrophage. Ho did Ph.D. study in the Institute of Immunology at Essen University, Germany from 1985 to 1988 , to study the genetic structure and biological function of HLA, especially the possible role of HLA expression in the development of leukemia. He received his Ph.D. degree in 1988, with the thesis on the abnormal expression of HL $\Lambda$ antigens in the leukemia (AML) cells. After returning to China, he was appointed as an associate professor of pathophysiology in the Department of Pathophysiology, Tongji Medical University, where he set up an HLA serological typing laboratory for tissue matching and forensic purposes, and taught immunopathology for medical students.

In 1990, Prof. Gong established the Department of Immunology in Tongji Medical Lniversity. He has been offered the position as Full Professor and Director of the Department since its inception. As the head of the Department, he has created therein an environment that is unusually rich in intellectual ferment and stimulation, which has greatly promoted the development of the research and teaching work in the Department. His research field involves transplant immunology and tumor immunology. He was one of the pioneers who introduced the DNA typing method to the tissue matching for bone marrow transplantation in China, to make the HLA typing more reliable and more cost effective. His adapted PCR-SSP typing protocol is widely adopted in China for tissue typing, and proven to be one of the most successful HLA typing method. In 1994, he and his colleagues found the cell membrane bound form of tumor necrosis factor is more effective and more specific to kill tumor cells, which is expected to be a new weapon to fight against tumor. In order to develop new method to overcome the difficulties facing transplantation, he organized a series of studies on induction of host tolerance to graft. Dr. Gong has made substantial effort in basic immunology research. In recent years, his work focuses on the $T$ cell direct recognition of allogeneic antigen. His work has been granted Major/Key program from National Natural Science Foundation of China (NSFC) and National Major Basic Research Foundation (973 program). Prof. Gong has published 218 original papers, and been the autthor and editor of 7 academic works. Besides his research work, Prof. Gong is one of the major initiators and coordinators of Chinese Bone Marrow Donor Bank. For his academic contributions and talent for organization, he was appointed to a Vice Director of Chinese Bone Marrow De-

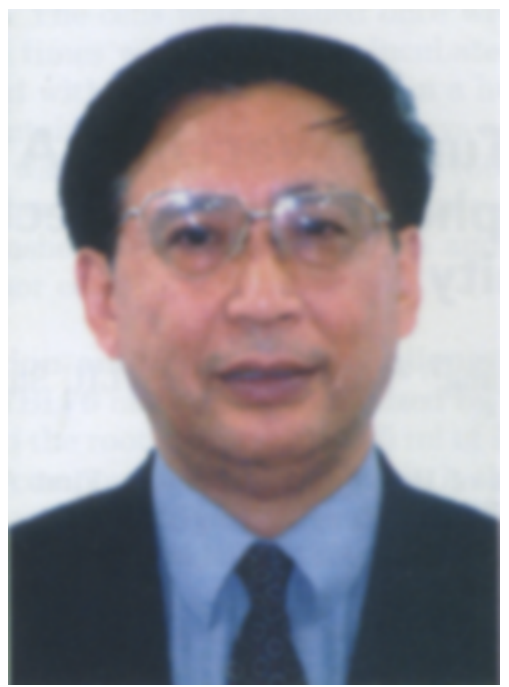

pository Expert Group. On another track, Prof. Gong has been working as a medical educator over 20 years. He has made an effort to make immunology teaching more efficient continuously, including educational innovation, novel teaching mode and means. He is Editor-in-chief of $3 \mathrm{im}-$ munology textbooks, which cover fundamental, medical and advanced immunology for medical students of different levels and specialties. He said: "To be both a scientist and a teacher is one of the most demanding task. It is essential for him to figure out the rules hidden behind immune phenomena, and tell the students what he knows, it is more important for him to tell the students why and how to explore the unknown world. The latter is the nature of our education". In 2003, he was titled to be "Famous Teacher" by National Department of Education, which is the greatest honor for educational professional in China.

Prof. Gong has earned national and international academic reputation. He is a member in numerous academic societies. While maintaining a very active research and teaching program, he is keen to serve academic societies. He is Chairman of Chinese-German Medical Association, Executive Member of Chinese Immunology Society, Chairman of Immunology Society of Ilubei and Wuhan. His efforts make the coordination and communication more effective and smooth among Chinese immunologists and international colleagues.

Prof. Gong is proud to be appointed as Editor-in-chief to "The Chinese-German Journal of Clinical Oncology". "This position is a challenge to me, because this is one of few academic journals published in English in China, and a more effective channel for Chinese specialists to communicate to their international counterparts compared with the journals published in Chinese. To make this bridge work better is my motivation", he said as asked for his comments on his appointment. 